\title{
LA CAMPAÑA ELECTORAL DE OCTUBRE DE 1982: EL CAMINO DEL CAMBIO*
}

José Ignacio Wert

\section{INTRODUCCION}

En este trabajo se pretende llevar a cabo una descripción y un elemental análisis de la campaña electoral que precedió a las Elecciones Legislativas celebradas en España el 28 de octubre de 1982. Me voy a ocupar de las condiciones de la convocatoria, de las coaliciones que se constituyeron (y las que se deshicieron), de los mensajes políticos, del papel de las encuestas, del clima político durante la campaña y, finalmente, de la valoración por parte de la opinión pública de las diferentes campañas.

Es obvio que la relevancia analítica de las campañas electorales está en función de la cristalización o fluidez en los apoyos políticos de las distintas fuerzas concurrentes $y$, en suma, de la incertidumbre sobre el resultado final. Entre las funciones que las campañas electorales cumplen ${ }^{1}$, predominaron

* Este trabajo se presentó originalmente en el seminario bajo el título general The Spanish Elections of 1982 and Its Implications: An International Conference, que se celebró en el Institute of Latin American Studies, de la Universidad de North Carolina, en mayo de 1983.

1 Me he ocupado del tema con alguna extensión en Medios de Comunicación y Vida Política, Madrid, Fundación Humanismo y Democracia, 1980; sobre las funciones de las campañas, pueden verse: KATz, E., "Platforms and Windows: Broadcasting's Role in Election Campaigns", en McQuaIL, D. (ed.), Sociology of Mass Comunication, Londres, Penguin, 1972; Patterson, T. E., The Mass Media Election, N. Y., Praeger, 1980; BLume, J. G., y McQuaIL, D., "The Audience for Election Television", en Tunstald, J. (ed.), Media Sociology, Londres, Constable, 1970; López GuerRa, L., Las campañas electorales en Occidente, Madrid, Ariel, 1977. 
en ésta de 1982 sin duda las expresivas sobre las conativas. Es decir, la campaña funcionó mucho más como un mecanismo de suscitar identificaciones y entusiasmos que como un medio para recoger votos. El resultado - la victoria del PSOE por mayoría absoluta - estaba prefigurado antes del comienzo de la campaña, y la incertidumbre se limitaba a conocer con exactitud el reparto de votos entre una UCD, cuya «energía» política se desvanecía a ojos vista, y una Coalición Popular cuyos límites de atracción electoral eran una incógnita ${ }^{2}$. Fue una campaña, en cualquier caso, intensamente vivida por la población, en la que la participación en mítines y actos de diversa especie desbordó las previsiones y que, en su decurso, dio pistas sobre el alto grado de participación e implicación electoral que se produjo el 28 de octubre.

\section{LA CONVOCATORIA. EL AVISO DE PERTINI}

En Madrid, el 11 de julio de 1982, se disputaba la final del Campeonato Mundial de Fútbol entre Alemania e Italia. En el descanso del partido (se non è vero, è ben trovato) se produjo aproximadamente el siguiente diálogo entre el presidente de la República Italiana, Sandro Pertini, y el primer ministro español, Leopoldo Calvo-Sotelo:

Pertini: Así que va a disolver usted las Cámaras y a convocar Elecciones anticipadas.

Calvo-Sotelo: Así es.

Pertini: De modo que ¿su partido tiene posibilidades de ganar las Elecciones?

Calvo-Sotelo: Prácticamente ninguna.

PERTINI: Entonces, ¿por qué disuelve usted?

Fin del diálogo. En efecto, la observación de puro sentido común hecha por Pertini no admitía contrarréplica y, sin embargo, Calvo-Sotelo sabía que no tenía otra salida que la disolución. En la trastienda de aquella decisión -inevitable a las alturas en que la conversación arriba reproducida tuvo lugar- estaba la desintegración del partido gobernante, la $\mathrm{UCD}^{3}$, y la inviabilidad de mantener una ficción de vida parlamentaria en un momento de profunda crisis económica $y$.política.

Hay que retroceder un par de meses para establecer las claves de la decisión que finalmente se formalizaría el 28 de agosto. Las fechas determinantes son:

${ }^{2}$ Cfr. mi trabajo "Las raíces del cambio", Cuenta y Razón, núm. 10, marzo-abril 1983.

${ }^{3}$ López Pintor se ha referido plásticamente a ella como a la "Crónica de una muerte anunciada". Cfr. "The October 1982 General Election and the Evolution of the Spanish Party System", en Spain at the Polls, AEI, Washington. 
23 de mayo: Elecciones al Parlamento de Andalucía; como estaba previsto, el PSOE obtiene la mayoría absoluta (52 por 100 de los votos); AP, extraparlamentaria en Andalucía hasta entonces, queda segunda con el 17 por 100, y UCD se convierte en el tercer partido, bajando desde el 31 por 100 que obtuvo en 1979 en la región a un testimonial 13 por 100. El descalabro centrista adquiere proporciones de cataclismo en las grandes ciudades (Sevilla y Málaga, sobre todo), donde UCD es literalmente barrida por el PSOE y AP.

Jumiosuliv: Calvo-Sotelo renunciz z la presidenciz de UCD y propone como sucesor al presidente del Congreso de los Diputados, Landelino Lavilla. La larga crisis cuya solución formal demora casi dos meses se resuelve con la aceptación de Lavilla bajo una insólita condición: acepta la presidencia del partido del Gobierno con una «cláusula devolutiva», en virtud de la cual si sus propuestas encuentran resistencias la presidencia volvería automáticamente a Calvo-Sotelo. Suárez se desentiende visiblemente de UCD y expresa en público su abierta discrepancia con el partido que fundó.

7 de julio: Oscar Alzaga, diputado de UCD, forma con una docena de diputados y otros tantos senadores de UCD, el nuevo Partido Demócrata Popular (PDP), que se define como de inspiración democristiana. Al abandonar UCD, el grupo promotor expresa su compromiso de permanencia en el Grupo Parlamentario Centrista y de apoyo político a Calvo-Sotelo. Al tiempo anuncia su intención de pactar con Alianza Popular la concurrencia a unas próximas Elecciones ${ }^{4}$.

31 de julio: Adolfo Suárez anuncia la fundación de un nuevo partido, el Centro Democrático y Social (CDS), con un manifiesto fundacional que define al partido como «de centro, progresista y reformista», con un especial énfasis en lo que llaman la «supremacía del poder civil» ${ }^{5}$. Con Suárez se va también una docena de diputados y algunos senadores, si bien su incorporación al CDS se realiza a lo largo de todo el mes de agosto en una táctica destinada a prolongar el interés informativo, que la prensa calificó como de «goteo».

Para acabar de complicar el panorama, Antonio Garrigues Walker, presidente de los «Clubs Liberales», anuncia también en el mes de julio la constitución del Partido Demócrata Liberal (PDL), que si bien no origina deserciones significativas en los Grupos Parlamentarios de UCD, contribuye al «ruido» periodístico sobre la desintegración del partido del Gobierno.

4 Véase el artículo de Oscar Alzaga (en El País el 7 de julio de 1982), "La superación del inmovilismo centrista".

s Véase manifiesto en El País, 1 de agosto de 1982. 
En estas condiciones, el mes de agosto - mes «oficial» de vacaciones políticas - fue un hervidero de rumores. El Gobierno había acabado la sesión parlamentaria invierno-primavera decididamente contra las cuerdas. De los 168 diputados con que UCD comenzó la legislatura, el grupo, tras las defecciones de Fernández-Ordóñez y sus seguidores para fundar el Partido de Acción Democrática (PAD) a finales de 1981; las de Herrero de Miñón y seguidores, integrados en AP en febrero de 1982, y todas las reseñadas arriba, quedaban bajo la disciplina política de Landelino Lavilla apenas 130 . Frente a dichos diputados, el PSOE contaba con el apoyo político en cuestiones básicas de no menos de 150 diputados, incluyendo además de los propios a los del PAD, PCE y buena parte del Grupo Mixto. Sólo un pacto parlamentario de cierto alcance hubiera permitido a Calvo-Sotelo acabar la legislatura. Y a menos de un año de la extinción del mandato, el PSOE no tenía el menor interés en comprometer sus posibilidades electorales en un pacto con un partido exangüe. Tampoco el grupo de Fraga hubiera bastado numéricamente para recomponer una mayoría. Si a todo esto se añade el temor (que tenía más de metus reverentialis que de análisis de posibilidades objetivas) de Lavilla y Calvo-Sotelo a que Suárez dispusiera de tiempo para organizar su partido, se comprende que el 27 de agosto, fecha del primer Consejo de Ministros después de la rentrée política, Calvo-Sotelo sometiera al Rey (de vacaciones en Mallorca) el Decreto de disolución de las Cortes Generales y la convocatoria de Elecciones para dos meses después.

La propia noche del día 27 de agosto una escueta comparecencia de CalvoSotelo ante la televisión anunciaba la decisión y daba abiertamente sus claves reales:

«... a partir de ahora el Gobierno que presido se vería obligado a entrar en pactos difíciles y artificiales, confusos para la opinión pública y necesariamente deformadores de sus propios criterios. No creo que ni el prestigio de las instituciones ni la eficacia de la acción del Gobierno, salieran ganando si yo me empeñara en mantener, con estos datos, la apariencia de una normalidad parlamentaria...» ${ }^{6}$.

La disolución y convocatoria fueron acogidas con calma e inocultable satisfacción por parte del PSOE y $\mathrm{AP}^{7}$ y con reticencias y resignación por parte de los nuevos partidos (CDS, PDP). En ambos casos, se reconoció lo inevitable de la decisión. El mundo empresarial criticó la decisión con cierta dureza -más retórica que otra cosa- ${ }^{8}$. El martes día 31, primer día de

- Alocución televisada de Leopoldo Calvo-Sotelo del 27 de agosto de 1982; $A B C$, 28 de agosto.

7 Véanse especialmente declaraciones de F. González en Wiesbaden (Alemania) -donde le sorprendió la disolución- en Diario 16 del 28 de agosto; Fraga en $A B C$ del mismo día.

- Declaraciones de C. Ferrer Salat y J. M. Cuevas en ABC, 28 de agosto; declaraciones de J. A. Segurado en Ya, misma fecha. 
operación de las Bolsas, tras la disolución, el clima de certeza de la victoria socialista y la inicial desconfianza que esto suscitaba se traducía en una baja del índice medio de Madrid y Barcelona superior a tres puntos.

\section{LAS COALICIONES Y LA FORMACION DE CANDIDATURAS}

El propio fin de semana en que se anunció la disolución comenzó una desenfrenada carrera hacia la formación de coaliciones electorales en el espacio del centro y la derecha. La legislación electoral española concede un plazo preclusivo para la formación de coaliciones electorales, que terminaba el 14 de septiembre 9 . La gran incógnita en este punto de las coaliciones era si el partido del Gobierno, ante el difícil trance electoral que se avecinaba, se avendría a las reiteradas invocaciones del líder de Alianza Popular a la «mayoría natural», que ahora admitía una versión más eufemística, en clave comparativa, como «fórmula a la portuguesa», y, en caso afirmativo, sobre qué bases podría reposar tal coalición. El resto de los acuerdos importantes (la concurrencia en coalición de AP con el PDP, el acuerdo del PAD con el PSOE) estaban prefigurados antes de la convocatoria y a reserva sólo de matizaciones técnicas ${ }^{10}$.

La disputa sobre la gran coalición de centro-derecha tuvo una inusitada intensidad dentro de UCD. Desde el principio, Lavilla proclamó su oposición a cualquier pacto «desnaturalizador de la idea de centro» ${ }^{11}$ y se erigió en portaestandarte de la opinión contraria a la coalición. Marcelino Oreja y Rodolfo Martín Villa sostuvieron la conveniencia del acuerdo. Entre tanto, AP mantenía abierta una oferta inespecífica de acuerdo y el PDP animaba públicamente a la gran coalición. Finalmente, el 7 de septiembre, UCD hacía solemne proclamación pública de su decisión de concurrir en solitario a las Elecciones excepto en el País Vasco (donde se alcanzó un acuerdo de concurrencia conjunta con AP, PDP y PDL), al tiempo que se mostraba de acuerdo en incluir en sus listas - como independientes- a personas del PDL. El día 11 de septiembre, Lavilla hacía una exaltada defensa de UCD ante 4.000 militantes reunidos en una convención en Madrid y repartía equitativamente torales.

${ }^{9}$ Artículo 31 del Real Decreto-ley 20/1977, de 18 de marzo, sobre normas elec-

${ }^{10}$ Alianza Popular y el PDP firmaron su coalición nacional el 13 de septiembre; el PSOE y el PAD suscribieron un comunicado de "identificación política" y presencia de miembros del PAD en las listas del PSE (no coalición formal) el 5 de septiembre, y el día 14 del mismo mes suscribieron un "pacto político". La reacción contra la presencia del PAD en las listas socialistas fue fulminante: el día 16 apareció en Diario 16 un duro artículo del colectivo Reflexiones Socialistas (portavoces de la corriente de Izquierda Socialista) titulado "iIndependientes o coalición?", en el que se auguraba un mal destino a la incorporación de los hombres de Fernández Ordóñez.

"Véanse $A B C$ del 2 de septiembre y El País del 5 de septiembre. 
sus ataques entre PSOE y $\mathrm{AP}^{12}$. Al día siguiente, el ex alcalde de Madrid y entonces ministro de Agricultura, José Luis Alvarez, abandonaba su cartera y UCD para integrarse en el PDP.

A estas alturas, cuando la «gran coalición» es sólo un «preterible» histórico, cabe valerse de las ventajas del estudio ex-post-facto y concluir que poco hubiera afectado a la mayoría resultante el que se hubiera llegado a un acuerdo. Mi hipótesis es que tal acuerdo hubiera conseguido prácticamente la suma aritmética del voto que finalmente se obtuvo por separado. Tal hipótesis tiene el aval empírico de una encuesta realizada a principios de septiembre por el Centro de Investigaciones Sociológicas ${ }^{13}$. En ella se concluía que una coalición electoral AP-UCD obtendría el apoyo de entre un 25 a un 30 por 100 de los votantes, y asimismo se demostraba que de entre las hipótesis de coalición que pudiera manejar UCD, ésta maximizaba el apoyo electoral entre los votantes centristas de 1979 , sin perjudicar la fidelidad en la intención de voto de los antiguos votantes de AP. Si esta hipótesis es correcta, la distribución final de escaños se hubiera modificado ligeramente en el sentido de que la coalición hubiera obtenido entre 130 y 134 escaños y el PSOE entre 186 y 190 . Desde cualquier punto de vista, las ventajas para UCD de la coalición eran obvias y no cabe decir, en descargo de la cúpula centrista, que no conocieran el posicionamiento del electorado. No fue tampoco un escrúpulo ideológico el que determinó la decisión, aunque se acudiera a él retóricamente ${ }^{14}$. Mi convicción es que las dos personas que pudieron inclinar la balanza mantuvieron un temor desmedido a que la coalición abriera un amplio espacio electoral a Adolfo Suárez y le diera una suerte de «razón objetiva» para su abandono de UCD. Hablo de temor desmedido porque ni la evidencia empírica ni el sentido común daban fundamento a tal hipótesis. Pero ni Landelino Lavilla ni Leopoldo Calvo-Sotelo aceptaron lo evidente y prefirieron «salvar la cara» frente a un supuesto compromiso moral en lugar de afrontar la única opción que daba alguna posibilidad de supervivencia y eventual reconstrucción al proyecto centrista. Los hechos han demostrado que al negarse al compromiso se estaba firmando el acta de defunción de UCD.

Pero aún antes del 19 de septiembre, fecha límite para la formalización de las candidaturas ${ }^{15}$, se produjeron dos hechos relevantes en el espacio del centro-derecha. El primero fue el incumplimiento por parte de los dirigentes provinciales de AP del compromiso nacional al que se había llegado con el PDP. La situación produjo una extrema tensión entre los dos par-

12 Véanse El Pais y Diario 16 del 12 de septiembre. Este último periódico tituló en primera página, a cinco columnas, "Ha nacido un líder", y dedicó un comentario editorial desmedidamente elogioso al discurso de Lavilla.

${ }_{13}$ Sondeo realizado entre el 3 y 5 de septiembre de 1982 sobre una muestra nacional de 2.400 personas. Banco de Datos del Centro de Investigaciones Sociológicas.

14 Declaraciones de Lavilla en El País del 10 de septiembre.

15 Artículo 30 del Real Decreto-ley 20/1977, de 18 de marzo, sobre normas electorales. 
tidos, y la palabra ruptura se llegó a manejar. El presidente del PDP, Oscar Alzaga, amenazó con retirarse de las listas y sólo una intervención de Fraga, recriminando a sus dirigentes provinciales y comprometiéndose a una «reparación moral y política» al PDP después de las Elecciones, salvó la situación ${ }^{16}$.

El otro incidente de cierta relevancia fue la ruptura del compromiso de UCD con el PDL de Antonio Garrigues. Tras el acuerdo político alcanzado el 9 de septiembre, el propio día 19 se manifestaba la imposibilidad de materializarlo por discrepancias en los nombres propuestos por el PDL. Este fue el último escándalo de UCD, y aunque sea difícil evaluar el deterioro electoral que supuso, proporcionó un elemento más de descomposición a la ya maltrecha imagen del partido centrista ${ }^{17}$. El PDL, excluido de las listas, decidió con buen sentido no concurrir a las Elecciones.

\section{«ISSUES»DE CAMPAÑA Y PROGRAMAS ELECTORALES}

Los programas electorales — como elemento de formalización de la oferta política - tienen en el contexto electoral español una reducida influencia directa en la determinación del voto. Dicho de modo más llano, nadie los lee. Estructuralmente están concebidos para no ser leídos, por otra parte: bastará una referencia a la extensión de los programas editados por los cinco partidos nacionales en las elecciones del 28 de octubre para comprenderlo:

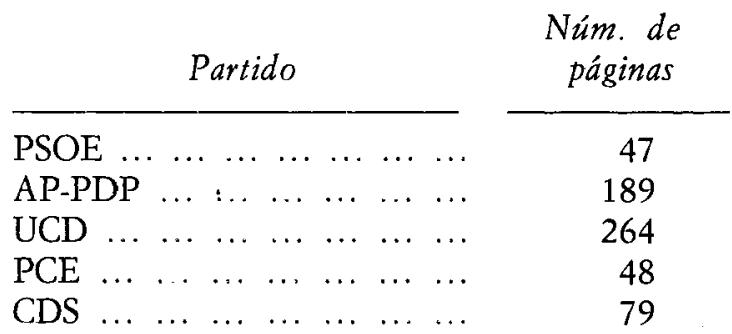

Sólo una concepción megalómana de la propia importancia podría dar visos de verosimilitud a la idea — que muchos políticos manejan- de que los programas electorales son bienes culturales de consumo masivo.

16 Véase Diario 16 del 22 de septiembre.

17 Aunque la reacción de Antonio Garrigues fue moderada, la prensa más próxima a él atacó inmisericordemente al sector azul de UCD, al que se atribuyó la responsabilidad de la ruptura. El día 20 de septiembre, Diario 16 (de inocultadas simpatías por Garrigues) publicada el editorial "Vota UCD, vota colza o las listas de Carrero", una soflama contra el partido centrista. Finalmente, la quebrada peripecia de este periódico con relación a UCD (véase nota 21) culminó con un artículo firmado por el director el domingo 22 de octubre titulado "Mi voto, para Lavilla". 
Sin embargo, los programas, a más de su relevancia analítica para los estudiosos de los partidos, ofrecen a los electores algunos indicios sobre la entidad de las ofertas políticas. Cualquier persona avisada podría hacer una estimación sobre los partidos a partir del lay-out de los programas. Frente a la cuidada concepción estética del PSOE, el informe burocrático (¡mecanografiado!) de UCD; frente al sólido aspecto del programa de AP.PDP, el «catecismo abreviado» del CDS con foto del titular incluida. Sólo resulta equívoca la edición del PCE, mucho más cuidada en fondo y forma que lo que la descomposición del partido pudiera llevar a pensar. Pero ésta no es la única ventaja del «centralismo democrático».

Estética aparte, los programas electorales presentaban una coincidencia básica: el énfasis en el tema del empleo. Las declaraciones liminares de todos ellos resultaban su carácter de problema prioritario y le dedicaban una extensión apreciable:

\section{Porcentaje del espacio redaccional de cada programa dedicado a economía y empleo}

\begin{tabular}{|c|c|}
\hline & $\%$ \\
\hline$\ldots \ldots \ldots \ldots \ldots \ldots \ldots$ & 35 \\
\hline $\begin{array}{llllllll}\text { AP-PDP } & \ldots & \ldots & \ldots & \ldots & \ldots & \ldots & \ldots\end{array}$ & 31 \\
\hline $\begin{array}{llllllllll}\mathrm{UCD} & \ldots & \ldots & \ldots & \ldots & \ldots & \ldots & \ldots & \ldots\end{array}$ & 32 \\
\hline 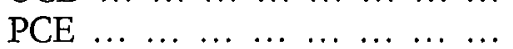 & 21 \\
\hline 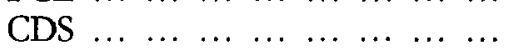 & 25 \\
\hline
\end{tabular}

En cuanto a las soluciones, como es clato, diferían radicalmente. En obligada síntesis, ésta sería la posición básica de cada uno de ellos:

PSOE: Creación de 800.000 empleos netos en el cuatrienio; reducción de la edad de jubilación (seis meses por año hasta el tope de los 59 años); reducción de las cargas sociales de las empresas; creación directa de empleo por el sector público a través de corporaciones locales; planificación concertada a través del Consejo Económico y Social previsto en la Constitución; reforma del sistema financiero: incentivos fiscales a la creación de empleo privado ${ }^{18}$.

AP-PDP: Saneamiento económico mediante la reducción del déficit público, control de la inflación y eliminación de la «hipertrofia del Estado»; la actividad privada motor exclusivo de la economía y de la creación de empleo; no se concreta un objetivo cifrado de nuevos empleos ${ }^{19}$.

18 "Por el cambio", Programa Electoral del PSOE, pp. 7 y ss.

19 "Es hora de soluciones", Programa de Gobierno de Alianza Popular en coalición con el Partido Demócrata Popular, pp. 15 y ss. 
UCD: Enfasis en la iniciativa privada para la creación de empleo estable; reducción del déficit público y crecimiento sostenido del P.I.B. durante el cuatrienio a tasas anuales entre el 3 y 4 por 100; continuación de la reconversión industrial; reducción sustancial de costes de la Seguridad Social e incentivos fiscales a la creación de empleo; flexibilización de las rigideces estructurales del mercado de trabajo; tampoco hay un compromiso cifrado de número de empleos ${ }^{20}$.

PCE: Creación de un millón de puestos de trabajo mediante un papel más activo y presente del sector público; democratización de la economía; reforma fiscal con mayor progresividad en los impuestos directos y aumento de un punto por año en la presión fiscal; reforma agraria mediante mejoras en la explotación y acceso del que trabaja la tierra a su propiedad y al control de los mecanismos de su transformación; Plan General de Reindustrialización, con protagonismo del sector público; planificación democrática ${ }^{21}$.

$C D S$ : Transformación de la estructura productiva mediante una nueva industrialización que permita tasas de crecimiento por encima del 4 por 100 anual; sectores estratégicos en esta nueva industrialización son la informática, electrónica, algunas ramas de la química, agroindustria, biología aplicada y nuevas energías; esta reindustrialización selectiva exige volver a tasas de formación bruta de capital comparables a las de los años sesenta mediante el estímulo al ahorro privado, el aumento del ahorro público y la reforma del sistema financiero; más inversión pública y contención de la inflación ${ }^{22}$.

Como se desprende de la síntesis anterior, las propuestas responden a la concepción económica global de cada uno de los partidos, y se caracterizan por su inconcreción, sin llegar a ser - si acaso con la excepción del correspondiente al CDS - un ejercicio de política de superoferta. En general, esta vaguedad de los programas económicos fue el foco más intenso de crítica por parte de los medios de comunicación ${ }^{23}$. El PSOE planteó un programa de corte socialdemócrata ortodoxo, si bien lleno de cautelas y prudencia en un intento de no provocar recelos en el sector empresarial: exclusión de nacionalizaciones con la excepción de la red de alta tensión y la eventual

${ }^{20}$ Programa Electoral (versión íntegra) de UCD, pp. 13 y ss.

${ }^{21}$ Programa Electoral del Partido Comunista de España (aprobado por el Comité Central del PCE en su reunión de los días 15 y 16 de septiembre de 1982), pp. 9 y ss.

${ }_{22}$ "España como debe ser", Programa Electoral del CDS, pp. 21 y ss.

${ }^{23}$ Véase editorial de Diario 16 sobre el programa de UCD el 28 de septiembre y comentarios al programa del PSOE en El Pais el 8 de septiembre; sobre el programa económico de AP, véase "El catecismo de AP", por Javier GrLsanz, en Cambio 16, núm. 567, pp. 82-85; $A B C$ del 22 de septiembre contiene un excelente cuadro-resumen comparativo de los programas del PSOE y AP; asimismo Cambio 16 , núm. 569 , p. 53 , para un adecuado resumen de todos los programas. 
de los Bancos intervenidos por el Fondo de Garantía de Depósitos, no más presión fiscal sobre las empresas y recuperación del excedente empresarial ${ }^{24}$. Por su parte, AP-PDP presentó una plataforma de tipo neoliberal, con explícito reclamo de fidelidad a los modelos (thatcherism y reaganomics) de propuesta conservadora para salir de la crisis ${ }^{25}$.

Aparte de los temas de economía y empleo, los programas electorales abordaban con diferente énfasis y planteamiento temas de libertades públicas, calidad de vida, defensa y seguridad, reforma de la Administración y política exterior.

Deben destacarse los amplios programas de desarrollo constitucional en materia de libertades públicas y derechos fundamentales presentados por el PSOE y el PCE, y la firmeza de las posiciones atlantistas (plena integración en el sistema defensivo de Occidente) de AP-PDP y UCD.

Probablemente, el tema de mayor interés a este respecto era qué tipo de compromiso estaba dispuesto a asumir el PSOE — que lideró la campaña «Por la paz, el desarme y la libertad» contra la entrada de España en la NATO- en torno a la política de defensa de Occidente, en la perspectiva - forzosamente realista - de su inminente llegada al Gobierno. Pienso que interesa transcribir literalmente los párrafos dedicados a estas cuestiones por el Programa Socialista:

«... La búsqueda de la paz, el desarme y la distensión, en la línea iniciada en 1975 por la Conferencia de Helsinki, puesta en crisis en los últimos años por la revitalización de la dinámica de bloques y la aparición de nuevos focos de tensión.

El PSOE propone, en consecuencia, la necesidad de eliminar del espacio europeo todos los misiles de alcance medio...

... El PSOE reafirma su filosofía contraria a la política de bloques militares que de hecho consagra la división del mundo en zonas de influencia perpetua, y se compromete a seguir luchando por un mundo libre y en paz, donde la cooperación, el intercambio y el diálogo Norte-Sur sustituyan a la tensión Este-Oeste.

... Una relación con EE.UU. en el marco de las relaciones con el mundo occidental... (que)... se orientará en una doble vertiente: por un lado aquella que afecta a la relación militar o de mantenimiento de la misma...

En este sentido, el Gobierno trabajará para lograr un mayor techo de autonomía para España, desvinculándola progresivamente en el plano militar del Bloque del Atlántico Norte. En consecuencia, y en la línea ya expresada anteriormente por el PSOE, en un primer momento

24 Véase A. PAPELL, "La victoria socialista y el poder empresarial, en Diario 16 del 10 de septiembre. Véase también el artículo de J. A. Segurado ("¿Cambio u obstinación?") en $A B C$ del 21 de octubre.

¿s Véase editorial del $\mathrm{Ya}$ el 19 de octubre, "Realismo frente a utopía". 
y como medida inmediata, se congelarán las negociaciones para la integración en la organización militar. En un segundo momento, se mantendrá el compromiso contraído por el PSOE de convocar un referéndum para que sea el pueblo español el que decida acerca de nuestra pertenencia a la OTAN» ${ }^{26}$. (Subrayados no originales.)

Tan larga cita tiene el propósito de ilustrar cómo el Programa Electoral Socialista supone una transición en sus posiciones políticas en la perspectiva del acceso inmediato al Gobierno. En efecto, estas posiciones equidistan de las adoptadas en el último Congreso del Partido (octubre de 1981) y las realmente implementadas en el Gobierno. En el 29 Congreso del PSOE, las posiciones expresaban aún un compromiso radical con la política de paz, distensión y no a los bloques, como queda de manifiesto en las siguientes proposiciones:

«Nos preocupa hondamente la instalación de los cohetes SS-20 en la URSS y la intención de la OTAN de instalar, como réplica, los Pershing-2 y los misiles Cruise en varios países de la Alianza...

... El Partido Socialista se opone a la interración de España en la OT $A N$... sólo asumirá una que considerará definitiva sobre el tema, si es sometido a referéndum consultivo previsto en la Constitución para temas de especial trascendencia... si cuando el PSOE llegue al Gobierno no se ha sometido el tema a consulta, el Gobierno socialista someterá a referéndum la pertenencia o no de España a la OTAN...

... Sistema que es compatible con una vinculación limitada, negociable y, por tanto, sujeta a plazos y condiciones con los Estados Unidos de América (renegociación del Tratado de Amistad y Cooperación), definiendo estrictamente los supuestos de utilización de bases... con un control total del Gobierno español sobre las instalaciones en nuestro suelo. Instalaciones que en el próximo acuerdo deberán reducirse sensiblemente. En cualquier caso, sigue siendo aspiración del PSOE la total desaparición de las bases extranjeras en nuestro te-t rritorio nacional» ${ }^{27}$. (Subrayados no originales.)

Es perfectamente claro cómo en los meses que van de un texto a otro se depura el lenguaje hacia una suerte de «compromiso apócrifo», que elude los planteamientos frontales. $\mathrm{Y}$ se trata evidentemente de un compromiso por cuanto las decisiones del Gobierno socialista en los tres temas planteados han sido la ratificación del Tratado con los Estados Unidos en términos idénticos a los negociados por el anterior Gabinete, salvo la adición de un codicilo que desvincula los aspectos defensivos de la integración en el dis-

26 "Por el cambio", Programa Electoral del PSOE, pp. 45-47.

${ }_{27}$ Anexo del Acta del 29 Congreso (Resoluciones), Partido Socialista Obrero Español, 21-24 de octubre de 1981, pp. 33-34. 
positivo defensivo atlántico; la aprobación de Felipe González a la «doble solución» en el tema de los misiles; y, finalmente, la neta decantación del presidente del Gobierno en favor de la presencia de España en la OTAN, si bien rechazando la integración en la estructura militar de la misma ${ }^{28}$.

Para finalizar este apartado, debe hacerse una breve mención a los planteamientos programáticos de los partidos nacionalistas más importantes, Convergència $i$ Unió (CiU) y el Partido Nacionalista Vasco (PNV).

Los primeros basaron su propuesta en la oposición a la LOAPA, la complitud del desarrollo del Estatut y la contribución a la gobernabilidad del Estado mediante una fuerte presencia catalana en Madrid ${ }^{29}$. El PNV, por su parte, basó su programa en la defensa y aumento de las cotas de autogobierno conseguidas, la oposición a la LOAPA y la defensa de la identidad cultural vasca («reuskaldunización»). Quizá el rasgo más sorprendente de este programa fue su apoyo a una despenalización limitada del aborto, teniendo en cuenta el carácter democristiano del partido y su afiliación a la internacional $\mathrm{DC}^{30}$.

\section{LA CAMPAÑA Y SUS MENSAJES, LAS ESTRATEGIAS DE COMUNICACION}

En este apartado se trata de examinar la estrategia de comunicación electoral de los principales partidos, los ejes o ideas-fuerza que cada uno destacó, así como los estilos y grado de personalización que se pusieron en juego. Una breve referencia al marco legal en que se desarrollan las campañas electorales en España permitirá comprender mejor lo que sigue.

La campaña electoral dura veintiún días. No hay limitación cuantitativa de gastos electorales y los mecanismos de control del dinero electoral son mucho más formales que efectivos. El Gobierno facilita igualdad de acceso gratuito a los medios públicos de comunicación a todas las candidaturas que concurran en al menos 25 circunscripciones, y no cabe la utilización mediante pago de estos medios (no hay, por tanto, publicidad pagada de los partidos en TVE, ni en las radios y periódicos del Estado). Hay franquicia postal para envíos de propaganda electoral. Los Ayuntamientos deben poner a disposición de los partidos lugares abiertos o cerrados para la celebración de mítines. Los partidos reciben subvención del Estado para gastos electorales en función del número de votos y escaños obtenidos por cada uno ${ }^{31}$.

Los recursos gastados por los partidos en esta campaña y su comparación con los de campañas anteriores, según los responsables de los mismos, fueron:

${ }^{28}$ Intervención del Presidente González en el Congreso de los Diputados con ocasión del debate sobre el estado de la nación, octubre de 1984.

${ }^{29}$ Véase La Vanguardia del 15 de septiembre.

${ }^{30}$ Véase Deia del 26 de septiembre.

31 Real Decreto-ley 20/1977, de 18 de marzo, sobre normas electorales, artículos 37 a 48. 
Autoestimación de gastos de campaña de partidos nacionales ${ }^{32}$

\begin{tabular}{|c|c|c|c|}
\hline & \multicolumn{3}{|c|}{ Millones de pesetas } \\
\hline & 1977 & 1979 & 1982 \\
\hline $\begin{array}{llll}\ldots & \ldots & \ldots & \ldots\end{array}$ & 500 & 1.100 & 1.129 \\
\hline AP-PDP $\ldots \ldots \ldots \ldots$ & 650 & 500 & 1.300 \\
\hline $\mathrm{UCD} \ldots \ldots \ldots \ldots$ & 1.500 & 1.300 & 1.500 \\
\hline $\mathrm{PCE} \ldots \ldots \ldots \ldots \ldots$ & 239 & 200 & 250 \\
\hline 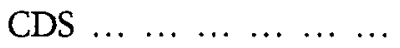 & - & - & 700 \\
\hline
\end{tabular}

En cualquier caso, estas informaciones deben acogerse con suma cautela, ya que los débiles mecanismos de control existentes no garantizan la veracidad de la contabilidad electoral exigida. Es segura la infraestimación en los gastos declarados por PSOE, AP-PDP y UCD.

El módulo habitual de distribución de estos recursos ronda en torno al 60 por 100 para publicidad (que se reparte por terceras partes entre prensa, radio y publicidad exterior) y el 40 por 100 restante para actividades de masas, reuniones, salarios de colaboradores, consultoría, etc.

En síntesis, éstos serían los rasgos de la campaña de los principales partidos nacionales:

\section{PSOE:}

El Partido Socialista hizo una típica campaña de ganador. Con fuerte inversión publicitaria, fundamentalmente en radio y exterior (5.000 vallas, 8.000 cabinas telefónicas, medio millón de programas, 10 millones de trípticos, 32.000 cuñas), el slogan fue único a lo largo de la campaña: «Por el cambio». En dicho slogan se resumen plásticamente las diferencias de este PSOE respecto al de 1977 ( «La libertad está en tu mano» y «Socialismo es libertad») y 1979 («Un Gobierno firme para un país seguro»). El PSOE trató con éxito de presentarse en esta campaña como un catch-all-party, única «alternativa eficaz a los gestores de UCD» ${ }^{33}$.

La estrategia de comunicación pasaba por una fuerte personalización en torno a Felipe González (a título de ejemplo valga decir que él sólo consumió prácticamente los treinta minutos de televisión disponibles), en quien

32 Fuente: Cambio 16, núm. 569, pp. 77-78; otras fuentes dan cantidades ligeramente diferentes. Véanse Diario 16 del 23 de septiembre, Ya del 9 de septiembre, $A B C$ del 24 de septiembre, El Pais del 9 de septiembre. Las mayores diferencias corresponden al CDS, que declaró sucesivamente una inversión de 200 millones (9 de septiembre), 500 millones ( 24 de septiembre) y 700 millones (22 de octubre).

33 Véase "Las raíces del cambio", cit., p. 132. 
se resumía el mensaje «de propuesta», dejando a otras figuras del partido (Alfonso Guerra y Javier Solana sobre todo) los ataques a los adversarios, que al final de la campaña adquirieron cierta intensidad. Por su parte, Felipe González, actuando en presidente del Gobierno avant la lettre a todo lo largo de la campaña, desplegó en más de 40 actos de masas sus dotes de seducción, apelando frecuentemente a la ética como motor del cambio. Dos frases, repetidas en casi todas sus intervenciones, pueden dar idea del tono y el estilo:

«El cambio es que España funcione... porque no funciona.»

«Este pueblo tiene derecho a la esperanza» ${ }^{34}$.

No puede dejar de mencionarse la magnífica organización de la campaña del líder, que recorrió casi toda España en un autobús especial a lo largo de los veintiún días. Los detalles rituales estaban calculados sagazmente para evitar situaciones comprometidas. Así, al final de las intervenciones de Felipe González, una niña o niño le hacía entrega de un ramo de rosas, con lo que se conseguía un efecto emocional... y se evitaba la posibilidad del saludo con el puño cerrado. "La Internacional» desapareció de la fonoteca del PSOE y en su lugar un jingle («Hay que cambiar») y una composición de música electrónica provocaban los efectos de entrada y salida.

En conjunto, la campaña del PSOE fue modélica en su diseño, inteligente en su estrategia y eficaz en su ejecución. No quiere esto decir que las elecciones las ganara el PSOE en la campaña, pero sí que ésta fue un digno remate de un trabajo político desarrollado competentemente en los tres años anteriores. La estimación pública de la campaña del PSOE fue altísima, como lo prueba el siguiente dato extraído de una encuesta postelectoral realizada por el Centro de Investigaciones Sociológicas ${ }^{35}$ :

${ }^{34}$ Véase entrevista a Felipe González de José Oneto y José Manuel Arija en Cambio 16, núm. 569, pp. 35-36; una buena "crónica de ambiente" de una jornada electoral de Felipe González es el artículo de Antxon Sarasqueta, "La Gonzalezmanía", en Cambio 16, núm. 567, pp. 51-55; una excelente muestra del estilo de González se encuentra en el libro de Víctor Márquez Reviriego, Felipe González, un estilo ético, Madrid, Argos-Vergara, 1982.

${ }^{35}$ Muestra nacional de 2.400 entrevistas realizadas entre el 2 y el 4 de noviembre; véase López Pintor, R., y Juster, M.: "Iniciando el análisis de las elecciones generales de octubre de 1982", REIS, núm. 20, 1982, pp. 155-168. 
- Mal gobierno de UCD ..................

$\begin{array}{r}\% \\ \hline 31 \\ 24 \\ 14 \\ 10 \\ 21 \\ \hline 100\end{array}$

2. AP-PDP:

La estrategia de comunicación de la coalición AP.PDP tenía dos claros nortes:

- Enfasis en el liderazgo de Fraga.

- La coalición, única alternativa al socialismo.

Secundariamente se trataba de dar realce a la coalición en sí misma, como modelo de cooperación política y modo de visualizar la desintegración de UCD. El más claro ejemplo de este objetivo fue una valla publicitaria, lanzada en la segunda fase de la campaña, bajo el slogan "Todos ganaremos con Fraga», en la que aparecían las fotos de Oscar Alzaga, Miguel Herrero, Alfonso Osorio y José Luis Alvarez. Todos ellos ex militantes de UCD y candidatos al Congreso por Madrid.

Los slogans sucesivamente empleados fueron:

1. Es bora de soluciones.

2. Todos ganaremos con Fraga.

3. Es la bora de Fraga.

El nivel técnico de la campaña (con un empleo de medios publicitarios muy similar al del PSOE) fue superior al de ocasiones anteriores, aunque lejos de la perfección. Los medios publicitarios destacaron la calidad del jingle, ciertamente el mejor de todos los empleados. En cambio, los programas de televisión resultaron elementales de concepción y confusos de contenido; esto último, como consecuencia probablemente de la necesidad de «enseñar» a todos los antiguos líderes de UCD unidos a la coalición.

La campaña del líder, Fraga Iribarne, fue tan intensa como la de Felipe González. Fiel a su estilo, no rehuyó los ataques al socialismo y las ironías sobre el €entrismo, alcanzando en ocasiones gran dureza verbal. Pero, al igual que en el PSOE, también hubo «reparto de papeles» y las frases más vitriólicas las pronuncio el joven secretario general de AP, Jorge Verstrynge. 
Fraga eludió cuidadosamente las referencias a la pena de muerte y en general a cualquier reforma de la Constitución. Sin embargo, pasó por momentos de dificultad cuando, con ocasión del descubrimiento de un presunto complot preparado para el 27 de octubre, empleó una frase de ambiguo sentido que fue ampliamente explotada por sus adversatios como exponente de veleidades autoritarias del líder de AP. En conjunto, no obstante, Fraga demostró en esta campaña bastante más autocontrol que en ocasiones anteriores.

En conjunto, la campaña de AP-PDP tuvo más fundamento estratégico que las anteriores y una aceptable ejecución, aunque a gran distancia de la socialista ${ }^{36}$.

\section{UCD:}

Resulta difícil evaluar la campaña de UCD con los parámetros habituales. Resulta incluso difícil describirla. Aunque suene a boutade, se diría que la función latente de la campaña de UCD fue demostrar que UCD no existía. El grado de desorganización existente (no hubo, propiamente, un gerente de campaña) permitió una gran confusión de mensajes y un despilfarro económico inconcebible a la vista de las perspectivas electorales. Por otra parte, las características personales del líder y su performance pública -ademanes suaves en la tribuna del Congreso, gritos estentóreos en los mítines- complicaban más las cosas ${ }^{37}$. Además, el «goteo» hacia otros partidos, los fracasos de la política de alianzas y la anómala relegación del presidente del Gobierno convertían la campaña de UCD en un ejercicio de sonambulismo político.

En este contexto, no es de extrañar que las más disparatadas iniciativas proliferaran. Desde el contrato millonario con una firma norteamericana de consultoría e imagen, que mantuvo a los líderes centristas en la convicción de que podrían ganar más de 50 escaños ${ }^{38}$, hasta los textos publicitarios que aparecían en la prensa ${ }^{39}$, pasando por una foto del líder para la campaña

${ }^{36}$ Véase el artículo "Las cuentas de los partidos", en Cambio 16, núm. 569, p. 77.

${ }^{37}$ En el artículo "Los cinco magníficos" (Cambio 16, núm. 569, p. 54) hay una cruel y atinadísima descripción de un mitin de Landelino Lavilla.

“... En los mítines de UCD no abunda la euforia. Lavilla tampoco consigue provocarla en demasía: suelta frases demasiado largas, plagadas de esdrújulos que la gente no parece entender bien. Sus seguidores esperan con ansiedad el momento en que el candidato toma aire, sigue, y comienza a apresurar el ritmo y a elevar la entonación para terminar la frase tamborileando las sílabas. Entonces, prorrumpen en aplausos y en algunos gritos estentóreos de los más entusiastas. Pero ¿qué ha dicho? El auditorio parece tener una receptividad más emocional que racional y cuando se le pregunta sobre el discurso del candidato suelta evasivas..."

${ }^{38}$ Los consultores pertenecían a la firma Isis Inc., vinculada a David Sawyer Asociados. El técnico de imagen fue el cubano Jeddu Mascaretto, asociado a Sawyer.

${ }_{39}$ Véase algún ejemplo de estos textos:

"España no es socialista. Y tenemos que romper la idea prefabricada de 
¡con los brazos cruzados! UCD utilizó en la campaña tantos medios publicitarios como los grandes aspirantes: 7.000 vallas, 9.000 cabinas telefónicas, 30.000 cuñas de radio. Los slogans fueron sucesivamente:

\section{Landelino Lavilla responde.}

\section{Responde. Vota UCD. El Centro.}

El primero se desarrollaba temáticamente en propuestas sectoriales. Landelino Lavilla «responde» a un parado, a un ama de casa, a un telespectador, etc. Textos densos, oscuros y aburridos competían en prensa y radio con los mensajes simples y directos de los adversarios.

Era tal la falta de convicción en la campaña y tales las críticas que, por ejemplo, el último programa de televisión se dedicó en una buena parte a explicar que no había «dos Landelinos», uno sosegado y reflexivo y otro jupiterino y altitonante, sino que el mismo hombre ante la multitud se transfiguraba, imbuido del místico fervor de sus convicciones centristas.

En suma, la campaña de UCD es digna de pasar a un manual sobre cómo no se deben hacer campañas electorales.

Por lo que se refiere a los restantes partidos, el PCE hizo una campaña en la que el puro afán de supervivencia frente a los riesgos de laminación electoral resultó demasiado evidente. Como demasiado obvio era su slogan «Para que nada se pare». La imaginación y buena resolución técnica de los programas de televisión no consiguieron enmascarar la profunda crisis de liderazgo y objetivos que atravesaba el PCE. El CDS, por su parte, realizó una campaña muy modesta en medios... y en ideas. El slogan base fue un «ingenioso» acróstico con las siglas: "Como debe ser». A última hora se añadió otro, «Asegurar el progreso», para marcar el carácter «progresista» del partido y diferenciarlo de UCD. Adolfo Suárez, que hizo una campaña pesonal muy intensa, insistió en la «primacía del poder civil» y propuso reiteradamente un «pacto de Estado entre las fuerzas democráticas» para garantía de la gobernabilidad. Lo que, desde su posición estructural, no dejaba de ser un ejercicio de ironía o de ingenuidad ${ }^{40}$. Debe, finalmente, destacarse la excelente calidad técnica de la campaña de Convergència $i$ Unió de Cataluña, pivotando en torno al slogan «Todo irá mejor si Cataluña es fuerte

que es inevitable el triunfo del socialismo." (Anuncio en El País del 22 de septiembre.)

"Hay una gran parte de españoles que no acepta el dilema entre la derecha conservadora y una izquierda todavía utópica e inmadura." (Anuncio en $E l$ País del 28 de septiembre.)

"La-realidad de Europa Occidental demuestra que los pueblos que más han progresado han sido precisamente dirigidos desde posiciones políticas similares a las nuestras." (Anuncio en El País del 29 de septiembre.)

40 Véase "El CDS está servido", en Cambio 16, núm. 567, p. 49. 
en Madrid», y promoviendo la figura de Miguel Roca i Junyent como posible aglutinador de un Gobierno de coalición ${ }^{41}$.

\section{EL CLIMA POLITICO DURANTE LA CAMPAÑA $Y$ LAS ENCUESTAS ELECTORALES}

Puede decirse que el clima político durante las tres semanas de la campaña electoral se hubiera aliado con la propuesta de cambio. En efecto, no se recuerda un período de campaña con más acontecimientos negativos (unos fortuitos, otros no) como el que se vivió en las primeras semanas de octubre.

Hubo en esos días inundaciones graves en Levante, Cataluña y CastillaLa Mancha. Hubo un recrudecimiento terrorista en el País Vasco. Y, sobre todo, el viernes 1 de octubre se descubrió un complot en el que estaban implicados tres jefes de Artillería ${ }^{42}$, preparado - bajo el nombre clave de «Operación Cervantes»- para ser ejecutado precisamente el día anterior a las Elecciones, el 27 de octubre. Cuando el sábado 2 de octubre se hace pública la situación, los medios de comunicación reaccionan con violencia contra el ministro de Defensa y el aparato de Inteligencia Militar. A partir de ese momento el golpismo gana relieve como issue de campaña. El lunes 11 de octubre se reúne la Diputación Permanente del Congreso de los Diputados a la que el ministro Oliart somete un informe sobre la situación ${ }^{43}$. La evidencia de que el supuesto golpe está bajo control sosiega los ánimos después de esta sesión. Pero esta reactualización del «miedo al golpe» está sin duda entre las claves de alta participación del 28 de octubre ${ }^{44}$. Finalmente, y para que no faltara de nada, el teniente coronel Tejero, cabeza del asalto al Congreso de los Diputados el 23 de febrero de 1981, funda desde la cárcel en que espera la revisión de su causa por un Tribunal civil el partido «Solidaridad Española», cuya lista por Madrid decide encabezar. No hay mecanismos legales que le impidan tal comparecencia y, pese a los esfuerzos del Gobierno, la Audiencia Territorial decide que tiene derecho a ser candidato. De cuantos acontecimientos desdichados precedieron al 28 de octubre sólo éste tuvo un final feliz: los 10.017 votos $(0,37$ por 100 de los votos válidos en Madrid) que refrendaron el «apoyo popular» al golpismo.

Las encuestas electorales son un tema recurrente de discusión en España cada vez que se acerca una campaña. El intenso uso político que se hizo

${ }^{41}$ En una encuesta realizada por EDIS pocos días después de las elecciones, el único electorado en cuya decisión parece haber pesado decisivamente el slogan es, justamente, el de $\mathrm{CiU}$ : un 9,8 por 100 de los votantes de ese partido mencionan el slogan como inductor de su voto; cfr. Elecciones generales 1982 (opiniones y actitudes políticas de los españoles), Madrid, Fundación Friedrich Ebert, 1983, p. 133.

${ }^{42}$ Véase Diario 16, $A B C$ y El País del 4 de octubre.

${ }^{43}$ Véase Diario 16 y El Pais del 12 de octubre.

${ }^{44}$ Esta hipótesis cuenta con cierto aval empírico a través de la encuesta citada en nota 41 ; cfr. op. cit., en p. 29. 
de ellas ante las Elecciones de 1979 motivó que el Grupo Parlamentario de Fraga introdujera en el Congreso, en 1979, una Proposición de Ley para disciplinar el uso periodístico de estas herramientas de investigación en períodos electorales ${ }^{45}$. Puede decirse que la ley no ha sido respetada ni por el grupo proponente, salvo en el aspecto que prohíbe la publicación de sondeos en los cinco días finales de la campaña ${ }^{46}$.

Pese a todo, el crédito social de las encuestas salió fortalecido del 28 de octubre. Contribuyó a ello el que la gente repara sólo en los titulares y, en la medida en que éstos reflejaban el triunfo socialista sin excepciones, las encuestas han ganado verosimilitud. La encuesta sin duda más influyente fue la que publicó El País el último día hábil, el 22 de octubre, y cuyo ajuste con la realidad electoral una semana después resultó notable ${ }^{47}$.

${ }^{45}$ Esa proposición, tras los correspondientes trámites parlamentarios, se convirtió en la Ley 14/1980, de 18 de abril, sobre Régimen de Encuestas Electorales; su contenido - con mejoras técnicas- se deriva de la Ley francesa 77-808, de 19 de julio de 1977, en la que se inspiraron sus proponentes.

${ }^{46}$ Los partidos utilizaron la técnica del tracking para filtrar las expectativas que en cada momento les convenían estratégicamente, sin observar los requisitos de la Ley. Véase encuesta facilitada por AP en $A B C$ y Diario 16 el 28 de septiembre. Alfonso Guerra, a su vez, dio a conocer dos encuestas del PSOE el 4 y el 18 de octubre ( $A B C$ del 5 de octubre, Diario 16 del 19 de octubre) rebajando prudentemente las expectativas de su propio partido... pero sin tomar la precaución de hacer que los totales sumasen cien. Todas estas manipulaciones provocaron una dura nota de ANEIMO (Organización Corporativa de las Firmas de Estudios de Opinión) en Pueblo el 20 de octubre, olvidando probablemente que las firmas asociadas estaban participando en las operaciones de "maquillaje demoscópico".

${ }^{47}$ Encuesta realizada por Sofemasa, S. A., Dara el El País sobre una muestra de 18.255 entrevistas; trabajos de campo entre el 16 y 19 de octubre. Publicada en $E l$ País el 12 de octubre (cuadernillo especial). La atribución de porcentajes, escaños y su comparación con los resultados reales es así:

\begin{tabular}{|c|c|c|c|c|}
\hline \multirow[b]{2}{*}{ Partidos } & \multicolumn{2}{|c|}{ Encuesta } & \multicolumn{2}{|c|}{ Voto real 28 octubre* } \\
\hline & $\%$ & Escaños & $\%$ & Escaños \\
\hline Participación $(\%) \ldots \ldots \ldots$ & & & & \\
\hline 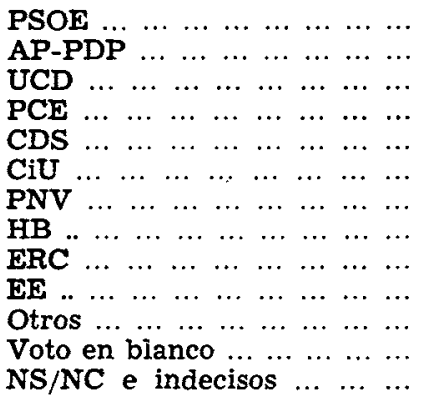 & $\begin{array}{r}42,9 \\
21,2 \\
5,7 \\
5 ; 2 \\
3,5 \\
2,2 \\
1,5 \\
1,0 \\
0,7 \\
0,6 \\
2,5 \\
1,3 \\
11,7\end{array}$ & 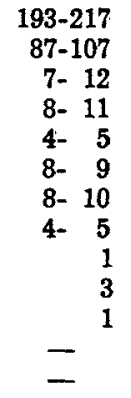 & $\begin{array}{r}48,4 \\
26,2 \\
7,1 \\
4,1 \\
2,9 \\
3,7 \\
1,9 \\
1,0 \\
0,7 \\
0,5 \\
3,5 \\
0,5 \\
-\end{array}$ & $\begin{array}{r}202 \\
106 \\
12 \\
4 \\
2 \\
12 \\
8 \\
2 \\
1 \\
1 \\
- \\
-\end{array}$ \\
\hline
\end{tabular}

* Fuente: Anuario El País 1983, p. 51. 
Junto a este acierto, hubo gaffes de importancia. Así, el panel electoral con tres oleadas publicado por El País y, paradójicamente, realizado por la misma empresa que realizó el del 22 de octubre ${ }^{48}$. Tampoco las tres oleadas encargadas por el «Grupo 16» pueden mostrarse como un prodigio de acierto ni de sensibilidad analítica ${ }^{49}$. Con todo, la palma en el desacierto hay que

${ }^{48}$ Panel dirigido por CITEP, S. A., realizado por Sofemasa, S. A., y publicado en El Pais los dias 14 de septiembre y 6 y 10 de octubre. Muestra de 2.460 entrevistas las dos primeras olas y 1.163 la tercera. Trabajos de campo:

Primera ola: 24-30 de agosto.

Segunda ola: 24-30 de septiembre.

Tercera ola: primeros días de octubre.

INTENCION DE VOTO EN \%

\begin{tabular}{|c|c|c|c|}
\hline Partidos & $\begin{array}{l}\text { Primera } \\
\text { ola }\end{array}$ & $\begin{array}{l}\text { Segunda } \\
\text { ola }\end{array}$ & $\begin{array}{c}\text { Tercera } \\
\text { ola }\end{array}$ \\
\hline Extrema derecha $\ldots \ldots \ldots \ldots \ldots$ & 0,9 & 0,3 & 0,6 \\
\hline $\begin{array}{lllllllll}\text { AP-PDP } & \ldots & \ldots & \ldots & \ldots & \ldots & \ldots & \ldots & \ldots\end{array}$ & 7,8 & 9,8 & 13,4 \\
\hline $\begin{array}{lllllllllll}\mathbf{U C D} & \ldots & \ldots & \ldots & \ldots & \ldots & \ldots & \ldots & \ldots & \ldots\end{array}$ & 5,6 & 3,2 & 3,5 \\
\hline $\begin{array}{llllllllll} & \operatorname{CDS} & \ldots & \ldots & \ldots & \ldots & \ldots & \ldots & \ldots & \ldots\end{array}$ & 1,6 & 1,5 & 3,2 \\
\hline $\begin{array}{lllllllllll}\text { PSOE } & . & \ldots & \ldots & \ldots & \ldots & \ldots & \ldots & \ldots & \ldots\end{array}$ & 33,5 & 34,0 & 35,4 \\
\hline $\begin{array}{lllllllllll}\mathbf{P C E} & \ldots & \ldots & \ldots & \ldots & \ldots & \ldots & \ldots & \ldots & \ldots\end{array}$ & 3,7 & 3,4 & 3,0 \\
\hline $\begin{array}{llllllllll}\text { Otros } & . & \ldots & \ldots & \ldots & \ldots & \ldots & \ldots & \ldots & \ldots\end{array}$ & 13,0 & 13,1 & 10,5 \\
\hline $\begin{array}{lllllllll}\text { Abstención } & \ldots & \ldots & \ldots & \ldots & \ldots & \ldots & \ldots\end{array}$ & 6,0 & 7,4 & 6,0 \\
\hline No sabe, no contesta ... ... ..... & 38,0 & 26,6 & 24,6 \\
\hline
\end{tabular}

${ }^{49}$ Serie de tres encuestas realizadas por Alef, S. A. sobre muestras de 3.000 entrevistas (las dos primeras) y 7.000 entrevistas (la tercera, que facilitaba distribución de escaños). Trabajos de campo:

Primera ola: 5-19 septiembre.

Segunda ola: 25-30 septiembre.

Tercera ola: $9-14$ octubre.

Publicadas en los números 563, 567 y 569 de Cambio 16, así como en Diario 16. RESULTADOS EN \% SOBRE CENSO

\begin{tabular}{|c|c|c|c|}
\hline Partidos & $\begin{array}{l}\text { Primera } \\
\quad \text { ola }\end{array}$ & $\begin{array}{l}\text { Segunda } \\
\quad \text { ola }\end{array}$ & $\begin{array}{l}\text { Tercera } \\
\quad \text { ola }\end{array}$ \\
\hline 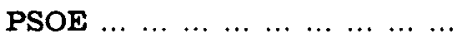 & 33 & 27 & 29 \\
\hline $\begin{array}{llllllllllll}\mathbf{A P} & \ldots & \ldots & \ldots & \ldots & \ldots & \ldots & \ldots & \ldots & \ldots & \ldots\end{array}$ & 7 & 10 & 10 \\
\hline 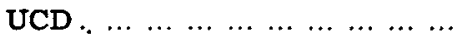 & 7 & 4 & 4 \\
\hline $\begin{array}{lllllllllll} & \operatorname{CDS} \ldots & \ldots & \ldots & \ldots & \ldots & \ldots & \ldots & \ldots & \ldots & \ldots\end{array}$ & 2 & 3 & 2 \\
\hline $\begin{array}{llllllllll}\text { PCE } . . & \ldots & \ldots & \ldots & \ldots & \ldots & \ldots & \ldots & \ldots & \ldots\end{array}$ & 5 & 4 & 5 \\
\hline $\begin{array}{lllllllll}\text { Otros } & \ldots & \ldots & \ldots & \ldots & \ldots & \ldots & \ldots & \ldots\end{array}$ & 7 & 7 & 5 \\
\hline $\begin{array}{lllllllll} & \text { Indecisos } \ldots & \ldots & \ldots & \ldots & \ldots & \ldots & \ldots & \ldots\end{array}$ & 39 & 45 & 45 \\
\hline
\end{tabular}


dársela a una fantasmagórica «Sociedad para el Estudio de las Elecciones» que facilitó, con toda suerte de avales académicos, las predicciones más desajustadas que imaginar quepa ${ }^{\text {so }}$.

Todo este «ruido» informativo, al que habría que añadir el provocado por «simulaciones», «Delphis» y otros artilugios predictivos, copiosamente esgrimidos por «boletines», «confidenciales» y demás media restringidos, llegó amortiguadamente al gran público. En efecto, según los datos de la encuesta postelectoral antes citada ${ }^{51}$, el 42 por 100 de los electores no llegó a tener conocimiento de ninguna encuesta. De entre el 45 por 100 que oyó hablar de ellas, sólo la mitad las leyó directamente. Los electores son escépticos sobre su influencia (el 33 por 100 piensa que influyen y el 46 por 100 que no) y, en cualquier caso, se muestran favorables a su publicación (el 49 por 100 es partidario de que se publiquen, frente a sólo un 14 por 100 opuesto a ello).

PREVISION DE ESCANOOS (tercera ola) *

\begin{tabular}{rlrlllllllllrr}
\hline PSOE.. & $\ldots$ & $\ldots$ & $\ldots$ & $\ldots$ & $\ldots$ & $\ldots$ & $\ldots$ & $\ldots$ & $\ldots$ & $\ldots$ & $\mathbf{2 1 7}$ & $(202)$ \\
$\operatorname{AP} .$. & $\ldots$ & $\ldots$ & $\ldots$ & $\ldots$ & $\ldots$ & $\ldots$ & $\ldots$ & $\ldots$ & $\ldots$ & $\ldots$ & $\ldots$ & 69 & $(106)$ \\
$\operatorname{UCD}$ & $\ldots$ & $\ldots$ & $\ldots$ & $\ldots$ & $\ldots$ & $\ldots$ & $\ldots$ & $\ldots$ & $\ldots$ & $\ldots$ & $\ldots$ & 18 & $(12)$ \\
$\operatorname{PCE}$ & $\ldots$ & $\ldots$ & $\ldots$ & $\ldots$ & $\ldots$ & $\ldots$ & $\ldots$ & $\ldots$ & $\ldots$ & $\ldots$ & $\ldots$ & 14 & $(4)$ \\
$\operatorname{CDS}$ & $\ldots$ & $\ldots$ & $\ldots$ & $\ldots$ & $\ldots$ & $\ldots$ & $\ldots$ & $\ldots$ & $\ldots$ & $\ldots$ & $\ldots$ & 8 & $(2)$ \\
$\operatorname{PNV}$ & $\ldots$ & $\ldots$ & $\ldots$ & $\ldots$ & $\ldots$ & $\ldots$ & $\ldots$ & $\ldots$ & $\ldots$ & $\ldots$ & $\ldots$ & 11 & $(8)$ \\
$\operatorname{CiU}$. & $\ldots$ & $\ldots$ & $\ldots$ & $\ldots$ & $\ldots$ & $\ldots$ & $\ldots$ & $\ldots$ & $\ldots$ & $\ldots$ & $\ldots$ & $\mathbf{5}$ & $(12)$ \\
$\operatorname{ERC}$ & $\ldots$ & $\ldots$ & $\ldots$ & $\ldots$ & $\ldots$ & $\ldots$ & $\ldots$ & $\ldots$ & $\ldots$ & $\ldots$ & $\ldots$ & 1 & $(1)$ \\
$\operatorname{EE} .$. & $\ldots$ & $\ldots$ & $\ldots$ & $\ldots$ & $\ldots$ & $\ldots$ & $\ldots$ & $\ldots$ & $\ldots$ & $\ldots$ & $\ldots$ & 2 & $(1)$ \\
$\operatorname{HB} .$. & $\ldots$ & $\ldots$ & $\ldots$ & $\ldots$ & $\ldots$ & $\ldots$ & $\ldots$ & $\ldots$ & $\ldots$ & $\ldots$ & $\ldots$ & 3 & $(2)$ \\
Otros & $\ldots$ & $\ldots$ & $\ldots$ & $\ldots$ & $\ldots$ & $\ldots$ & $\ldots$ & $\ldots$ & $\ldots$ & $\ldots$ & $\ldots$ & 2 & $(-)$ \\
\hline
\end{tabular}

* Entre paréntesis, a la derecha, el número realmente obtenido.

${ }^{50}$ En una presentación de Miguel Martínez Cuadrado (Off the record del 4 de octubre) se facilitó esta composición "probable" del Congreso de los Diputados:

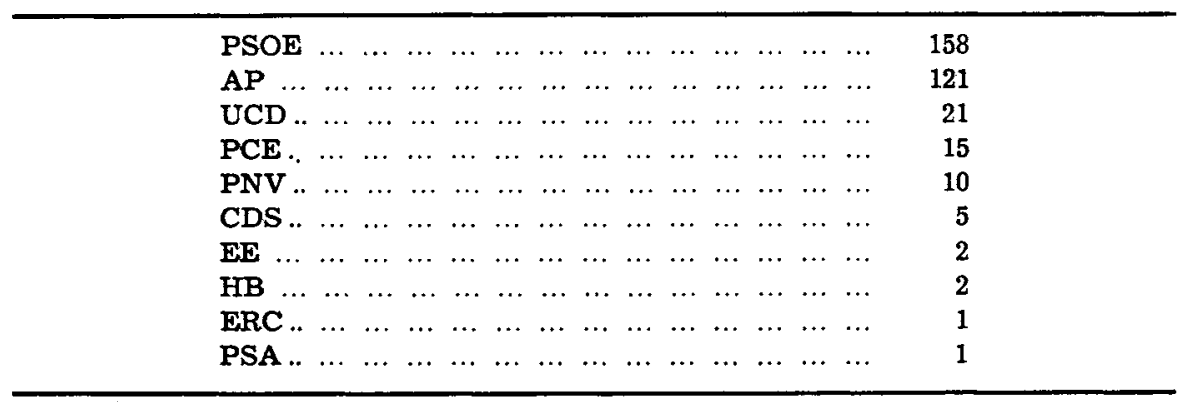

51 Véase encuesta citada en nota 35. 


\section{CONCLUSION}

A lo largo de toda esta descripción he tratado de poner de manifiesto los rasgos más salientes de una campaña que iba a cambiar significativamente el curso político del país. Queda por decir que es mi convicción, avalada por las periódicas consultas a la opinión pública a que tuve acceso antes, durante y después de la campaña, que en su curso no se modificaron sustancialmente los alineamientos políticos que se dibujaban antes de la convocatoria, pero sí se generó un clima -en parte inesperado- de entusiasmo, esperanza, angustia y compromiso. Nunca, ni en los momentos inaugurales del nuevo régimen, se había vivido con tanta intensidad la política. Pienso que - de distintas maneras - la gente percibió que se avecinaba un cambio no sólo de partido gobernante sino también de equilibrio político. Tras el fracaso de UCD, como ha señalado agudamente López Pintor, en ofrecer un «liderazgo para afrontar el reto de la modernización política de la derecha española» ${ }^{52}$, el 28 de octubre supone en muchas cosas una vuelta a empezar. Yo creo que así lo percibió el electorado a lo largo de la campaña y de ahí la sorprendente tasa de participación con que se abrió esta página de nuestra historia nacional.

52 "The October 1982 General Election...", cit. en nota 3. 